\title{
DEPLOYING \& MANAGING PERVASIVE COMPUTING ON CITY SCALE
}

\author{
Thomas Linner $^{1 *}$, Alaguraj Shrikathiresan ${ }^{2}$, Thomas Bock ${ }^{1}$ \\ ${ }^{1}$ Chair for Building Realization and Robotics, Technische Universität München, Germany \\ ${ }^{2}$ Building Technology and Construction Management, IIT Madras \\ *Corresponding author (thomas.linner@br2.ar.tum.de)
}

\begin{abstract}
In this paper, demographic change and ageing societies are identified as potential drivers for the development and implementation of pervasive technologies in our environment. Computers and Microsystems have become smaller and cheaper and become a part of our life and society. Wearable Robots, advanced prosthetics and sensor implants even aim at making human beings part of those developing cyber environments. We think that strategically guided and joint research has to be done and therefore give an overview of the subject and show that advanced BIM and structured environments play a role as core technology in efficiently deploying and managing pervasive computing and assistive environments on city scale.
\end{abstract}

Keywords: Pervasive Computing, Ubiquitous City, Ambient Assisted Living, Building Information Modeling

\section{INTRODUCTION}

Better medicinal and health facilities are extending the life expectancies all around the world. The double demographic change being experienced in many developed countries demand for more life support system and other assistance technologies [1]. Meanwhile the advancements in pervasive technology have made computers much smaller thereby making it possible to embed them into everyday objects [2]. Pervasive Technology becomes a part of our life and society. Wearable Robots, advanced prosthetics and sensor implants even aim at making human beings part of the developing assistive cyber environment [3]. As envisioned by Shirow Masamune's Manga classic "Ghost in the shell" the borders between man and advanced technologies shrink creating a 2029 Cyber Society [4]. Although it is not our main research aim, interesting relations between science fiction and science fact are discussed in [5]. However, we think that the integration of pervasive technology obviously becoming our 4th cultural technology [6] is a highly interdisciplinary task, challenging the next generation of engineers from various backgrounds. We think that strategically guided and joint research has to be done we and give an overview of the subject based on the latest and most advanced pervasive technology concepts in this paper. In Section 2 we show that demographic change is a main driver for the development of pervasive technologies. In Section 3 we outline that pervasive technologies are today developed for dedicated scales (assistive home, smart mobility, smart urban space) and will be cross-related and integrated to ubiquitous cities in the near future. In section 4 we show that advanced BIM and structured environments play a central role in efficiently deploying pervasive technologies. In chapter 5 we summarize the findings.

\section{DEMOGRAFIC CHANGE AS DRIVER FOR PERVASIVE TECHNOLOGY}

The demographic statistics on Fig.1 show that the percentage of people above 65 years is raising all around the world and Japan is expected to have $37 \%$ of its population above 65 years by 2050 [7]. Traditionally Japan's Shinto Religion values the elderly with great respect and care for the elderly is usually provided at home by the family members [8]. Like in EU countries placing the elders at a nursing or an elderly home at an old age is not considered ideal in Japan. The current double demographic change makes home care highly impractical. Hence there is a high demand for technological aids for the continued home care of the elderly. The concept of life support systems and assistance technologies based on those 
ideas exists since the 1980's [8]. This field of assistance technologies has improved vastly in the recent years ranging from ubiquitous health monitoring systems to robotic systems and cybernics. Apart from these, ubiquitous technologies embedded across the urban fabric can extended the support for the elderly even outside the homes and into the city public spaces and thereby making environments more accessible and inclusive for an ageing society [9] [10]. All in all, demographic change and ageing societies can be identified as potential drivers for the development and implementation of pervasive technologies into our environment.

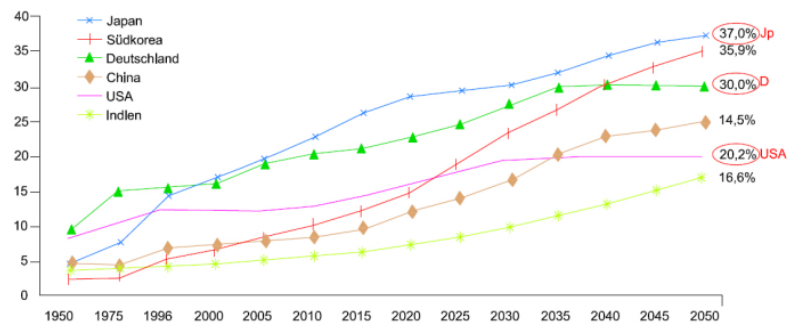

Fig 1 Increasing percentage of People above 65 years of age

\section{PERVASIVE COMPUTING ON VARIOUS SCALES: HOME, CITY, MOBILITY}

Pervasive technologies increasingly help elderly people to live independently in their home environment. However, this will not mean, that aging people will be living without restrictions, claims and demands [11]. As assistive technologies strengthen the skills of elderly people, they will demand for pharmacies, doctors, hospitals, social service, business, healthcare centers and other activities and services delivered in the city or the neighborhood even more. It is important to motivate elderly people to keep up physical activity and mobility from the home to the neighborhood or city [12]. On the one hand this strengthens physical, cognitive and psychic conditions and thus can serve as a means of prevention. On the other hand this mobility between the various scales is important to keep up value creation as during mobility we buy goods and acquire services thus spending money: shopping, leisure, events, short trips etc [8]. From this point of view and also from a very human point of view it is extremely important that we not only develop pervasive technologies that serve a particular scale but that we start to create strong interlinks between assistive homes, smart mobility and smart urban spaces. A system with a high degree of interlinks between those scales through advanced technologies we can then call a Ubiquitous City (Fig 2). In this chapter we outline concepts and strategies implemented on a dedicated scale. As in Japan the degree of pervasion of homes, city and mobility devices advances rapidly compared to other countries we use examples from Japan to explain major tendencies. The authors have analyzed those examples during a research visit in Japan in December 2010

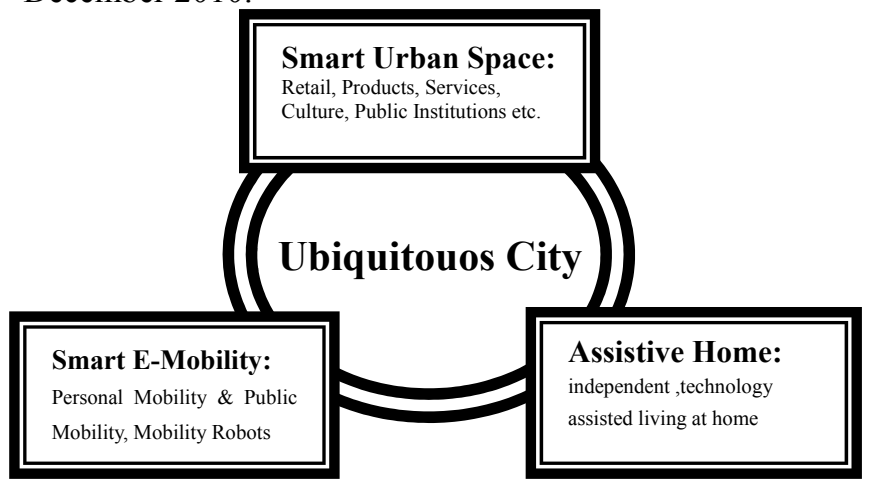

Fig. 2 A system with a high degree of interlinks between scales (smart homes, smart mobility and smart cities) through advanced technologies can be called a Ubiquitous City.

\subsection{Assistive Homes}

As the last century witnessed the commercialization of automobiles this century is expected to witness commercialization of robots for domestic use. Currently robots are only used in manufacturing and industrial sector. But as the robots enter into the domestic sector it will demand a change in the architectural space where robots and human can co exist and operate more effectively. The Wabot house project developed at Waseda University, aims to find a balance in architectural space for the co existence of robots and human [13]. Fig.3 shows the Wabot House project with the architectural designed for the coexistence Robots and Human where the floors are embedded with RFID technology to facilitate navigation of domestic robots within the architectural space. Fig.4 shows an environment cohabited by robots and Human and the dynamic movements within the space. 


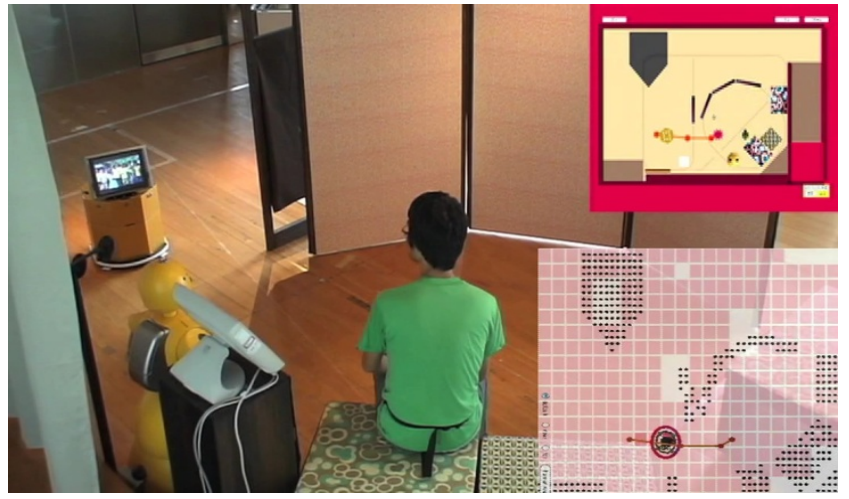

Fig 2 Wabot House Project, Waseda University

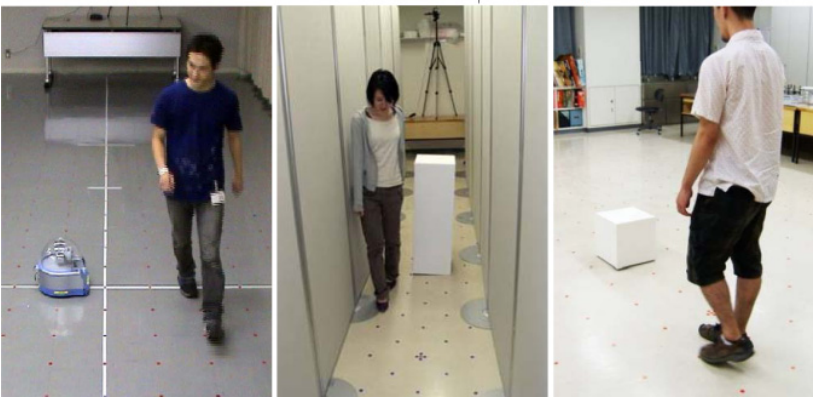

Fig 3 HER Group is researching on the interrelations of Humans and

Robots in specific environments; it is expected that the permeation of robotics in everyday life is inexorable

Fig. 5 shows the Twendy-one Robot at Prof.Sugano laboratory in Waseda University. Twendy one was a symbiotic robot designed especially to help the ageing society by performing every day activities within the architectural space. The unique design of the Twendy-One robot enables it to manipulate different objects and also to hold and lift the elderly when required.
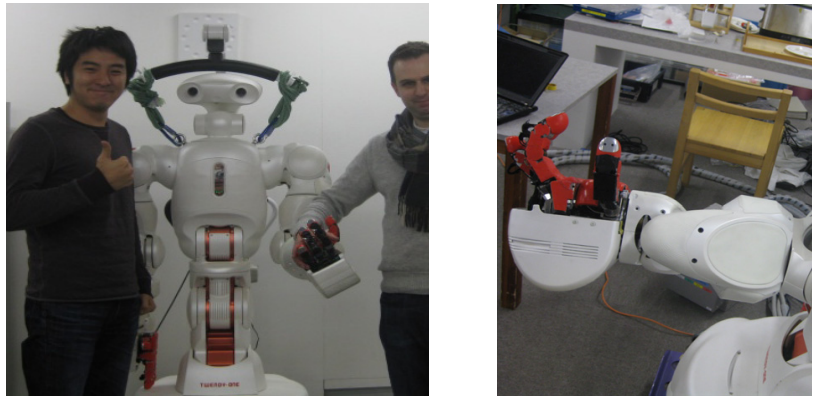

Fig 4 Twendy-One Robot and highly dexterous hand

In order to create a Ubiquitous environment Prof. Ken Sakamura created T-Engines as part of TRON Research project. T-Engine (Fig. 6) is the hardware that can be embedded into everyday home appliances and other sensors [2]. The appliances embedded with $\mathrm{T}$ Engines couples with the ITRON operating system (Middleware/ Software) form a part of ubiquitous home environment.
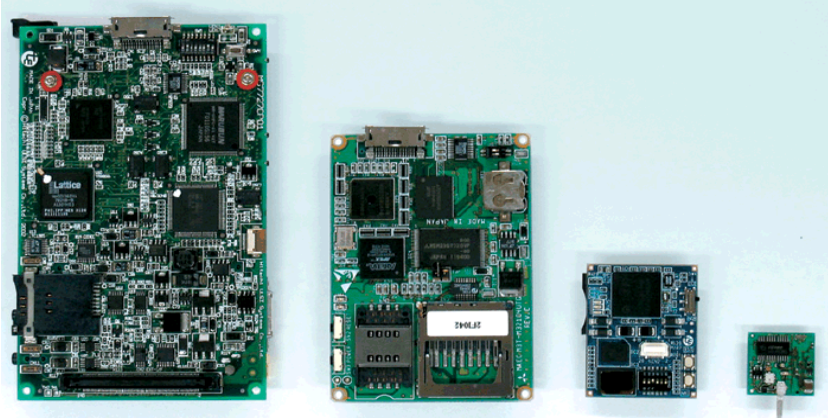

Fig 5 T Engine hardware components for use in smart objects and smart appliances, K. Sakamura [3]

\subsection{Smart Urban Space}

As part of the U Japan Strategy to create a ubiquitous city space, the Japanese government has embedded Ucodes or ubiquitous id tags into the urban environment one can access the required information using a ubiquitous communicator. More than thousands of ubiquitous tags have been embedded in the district of Ginza to create rich urban information. Embedding Ucodes in an urban fabric has many applications like sightseeing support, emergency information, robot navigation, positioning, etc

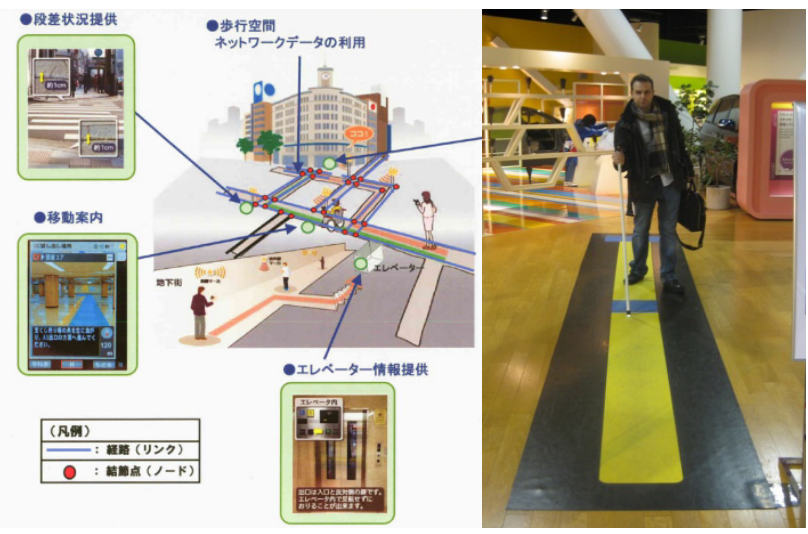

Fig 6 Tokyo ubiquitous technology project at Ginza and Toyota Assistive Crutch

Fig. 7 shows an Assistive crutch and a specially designed ubiquitous strip laid on public space in Japan to assist in safe mobility for the visually impaired and elderly people. The crutch embedded with sensors is always aware of its 
position as well as the obstacles in a ubiquitous urban environment. It guides the user by reading information embedded in the ubiquitous environment and also detects and notifies the obstacles ahead. It is also capable of notifying other vehicles on the road to slow down when the person uses the pedestrian crossing.

Fig. 8 shows the Robot town concept developed by Prof.Hasegawa where a robot serving an urban space instead being made complex, it is made simple and is guided with the help of sensors, cameras and RFID tags embedded onto the urban space. A town management System is created with the input and data from surveillance camera, RFID tags and other embedded sensors [14]. The robot then access the Town management system in order to navigate and complete the task provided.

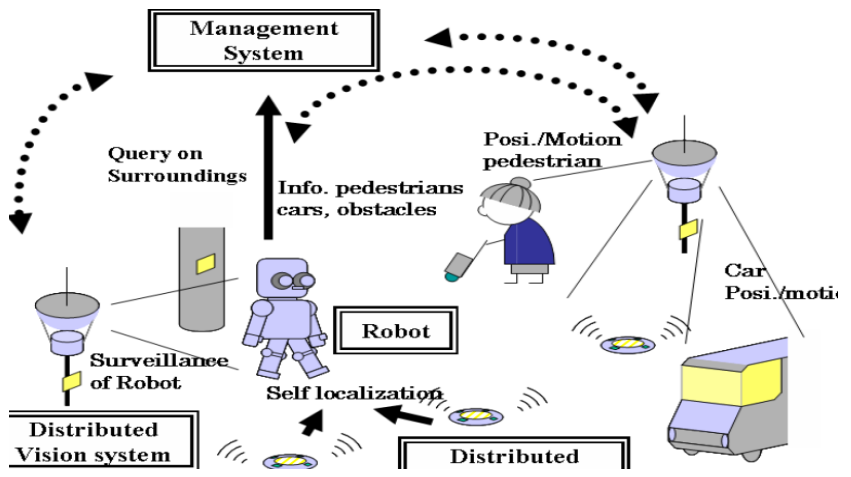

Fig 8 Robot Town Concept and Town Management

Fig. 9 shows the concept of Robot Town being experimented in Prof.Hasegawa laboratory at a smaller scale before being tested for an urban environment. Objects in the cabinet are embedded with RFID tags to guide the robot being tested in the lab.

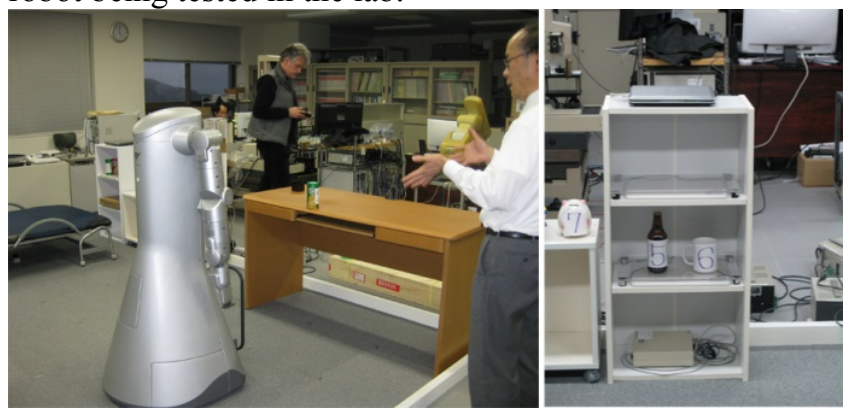

Fig 9 Robot Town Experimental setup with smart shelves providing structured environments for robots on a smaller scale
As a part of U-Japan strategy some restaurants in Tokyo have RFID tags embedded onto their plates and other dishes thereby providing an innovative and easy way for billing just by scanning the plates bringing the concept of just-in-time just-in-sequence into daily life (Fig.10).
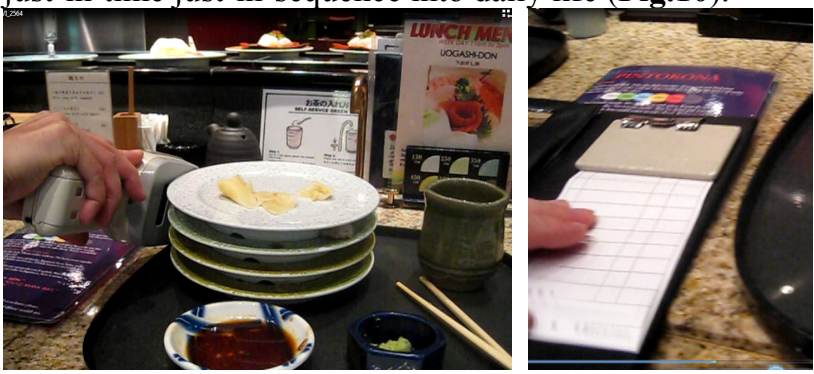

Fig 10 RFID tags and E-based super fast billing in restaurants

In addition to communication mobile phones had become an important tool for information in a ubiquitous society with the ability to access information anywhere and anytime.

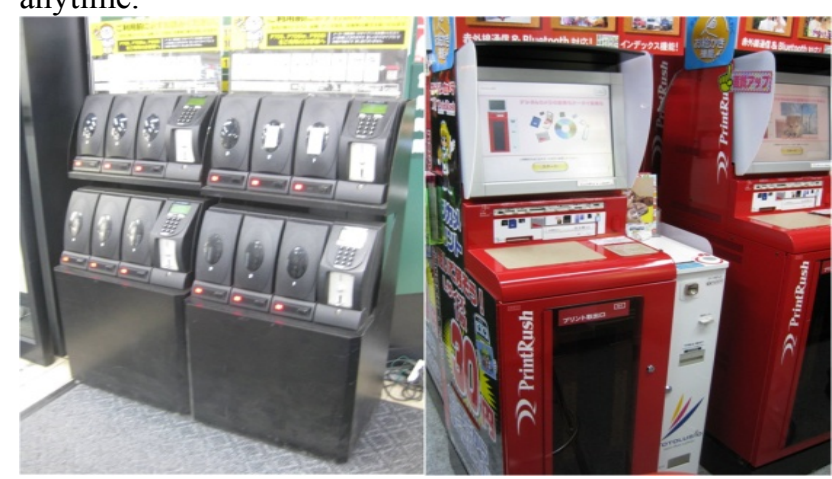

Fig 11 Mobile Charging and Ubiquitous Access Points

Fig. 11 shows the mobile charging stations integrated into the urban space in order to help the people stay connected all the time. Also Fig.11 shows the access points installed in public spaces where people can get any information and print required information. 


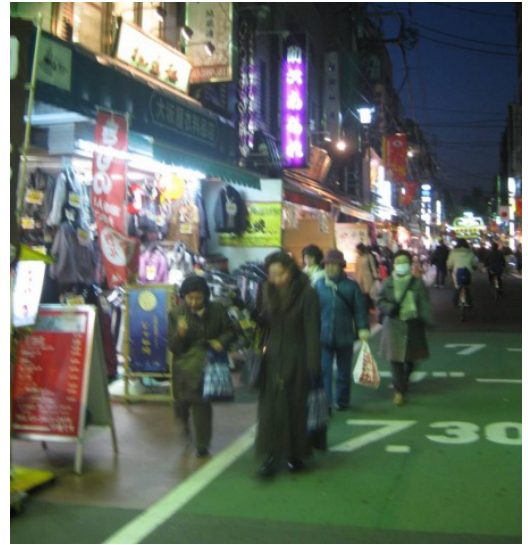

Fig 12 Sugamo, barrier-free Shopping District for elderly in Tokyo

In an ageing society the mobility of the elders become very important as the economy of countries with shrinking working age group would soon depend on the spending power of the elderly. Few areas like the Sugamo shopping district of Tokyo as shown in Fig.12 clearly illustrates that a barrier free and elder friendly environment play a major role in bringing the older people to the urban space and integrating them as a part of it. Even though every space cannot be same as the Sugamo shopping district ubiquitous technology embedded into the urban fabric would provide great assistance to the aged and disabled. Fig.13 shows an entrance terminal for a subway station and a ticketing terminal which are embedded with ubiquitous technologies to read contactless RFID cards and it was also designed barrier free to be accessible to people on the wheel chair.
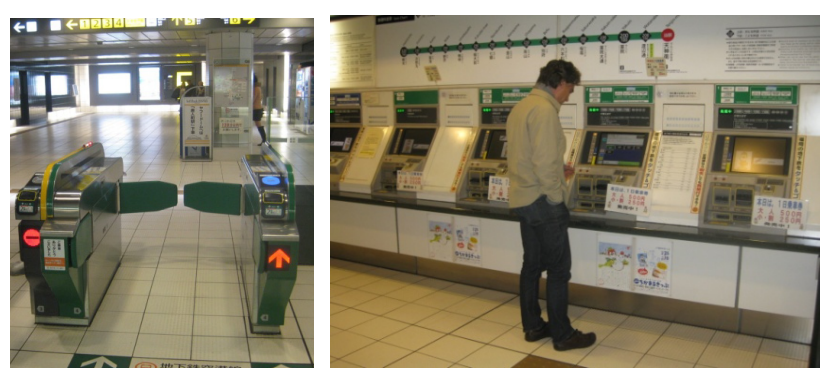

Fig 13 Subway Ticketing Terminal and Subway Entrance Portal of barrierfree Sub-way in Fukuoka

\subsection{Smart E-Mobility}

For a ubiquitous or $\mathrm{U}$ city to be complete it also needs a new system of ubiquitous mobility in addition to ubiquitous home and ubiquitous urban spaces. The ubiquitous mobility becomes an integral part in increasing the mobility of the elderly outside the homes. Even though the assistance technologies and robotic systems provide care for the elderly at home, often there is a need for occasional visit to the doctor or may be a stroll outside the home. Conventional modes of mobility are often inconvenient for elderly use. This demands new modes of mobility which are currently being explored by all major automobile industries. One such prototype called iReal by Toyota is illustrated in Fig. 14. These ubiquitous mobility systems help in easing the problem of transport faced by the elderly as they are more flexible and convenient than the conventional automobiles. Further these personal mobility vehicles can adapt to different situations and scenarios by capable of switching to driving, walking or cruising mode. As a result these devices provide an excellent mobility option for the elders even in the indoors.
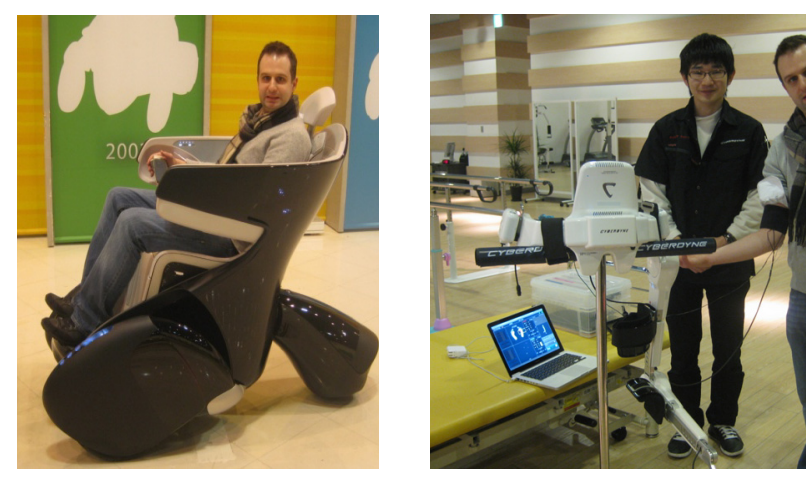

Fig 14 Toyota iReal (Future Ubiquitous Mobility) \& HAL - Hybrid Assistive Limb (Cyberdyne)

Cybernics [15] is a new research field which aims in assisting the elderly and disabled. Cybernics integrates the fields of neuroscience, robotics, systems engineering, ICT, ergonomics, sensor engineering, physiology and psychology to create a Robot Suit also known as HAL (Hybrid Assistive Limb). Fig. 14 shows an image of HAL, the cyborg type robotic suit for enhanced mobility and assistance of the elderly and disabled. It is called hybrid as it provides two control systems voluntary and robotic. HAL basically increases the physical capabilities of the user just by wearing it. It acts as an exoskeleton to perform the tasks beyond the person's physical capabilities. HAL has sensors attached to skin of the user which detects even the weak bio-electric signals on the skin surface. The movement of the HAL robotic suit is controlled by the 
neuron signals from the brain. As a person on a HAL suit intends to move brain sends out motoneuron signals to the muscles which are detected by the sensors which enable the robotic suit to complete the intended movement. This technology makes mobility more voluntary and intuitive.

\section{STRUCTURED ENVIRONMENTS: ROS/GAZEBO}

Building Information modeling is one of the recent developments in architecture, construction and engineering which help to visualize, support and manage the buildings during design construction and operation respectively [16]. But the developments on the field of pervasive computing had made the buildings more complex than ever resulting the current BIM tools obsolete as they do not have the options to integrate the sensor data and other pervasive technologies. Also in a pervasive environment there is a need for the building model to interact with the surroundings in real time. Mahdavi's research on sentient buildings illustrate that for the building to be intelligent and proactive the building model should be able to read inputs from the wide array of sensory network and update itself on real time [17]. Thus the requirement to access and control the various sensors and computers in a ubiquitous environment brings out need for a middleware. Robot Operating System (ROS) is one such middleware to enable the control over the various sensors and pass information between them in real time [18]. ROS uses a stimulator called Gazebo to create a model for a ubiquitous environment. Modeling in Gazebo is done by considering the building as an immobile robot with various joints and links. Creating a model using the concept of joints and links enable the building model to be more dynamic and update on real time based on the sensor information. With proper mechatronic systems this also gives the option to control the dynamic parts of the building from a remote location. Also this ROS/Gazebo is more suited to an environment cohabited with robots as shown in Fig.15 where these tools simplify the complexity required for the robot in order to successfully navigate the architectural space and perform the required tasks. This is done by creating a model in unified robot description format (urdf) which not only describes the visual properties about the building but also defines the inertial properties and the collision boundaries for each object in the model. Fig.16 shows the snap shot of the xml codes describing the visual, inertial and collision properties of the model.

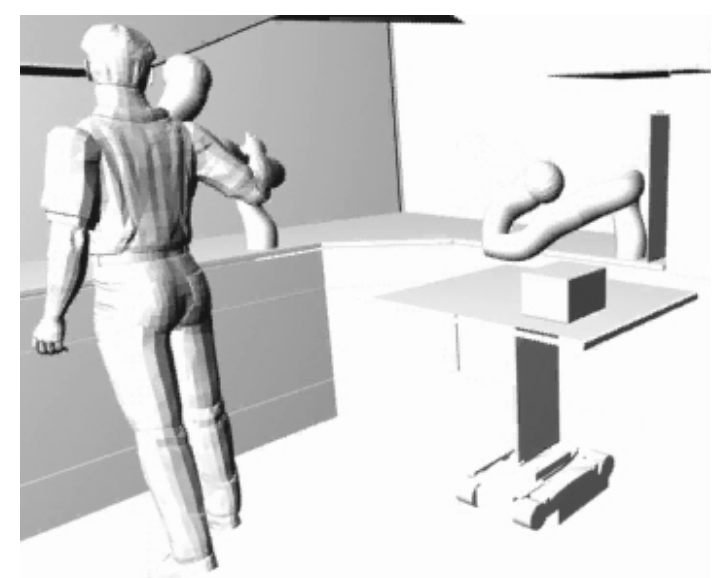

Fig 15 Robotic environment modeled in Gazebo using concept of links

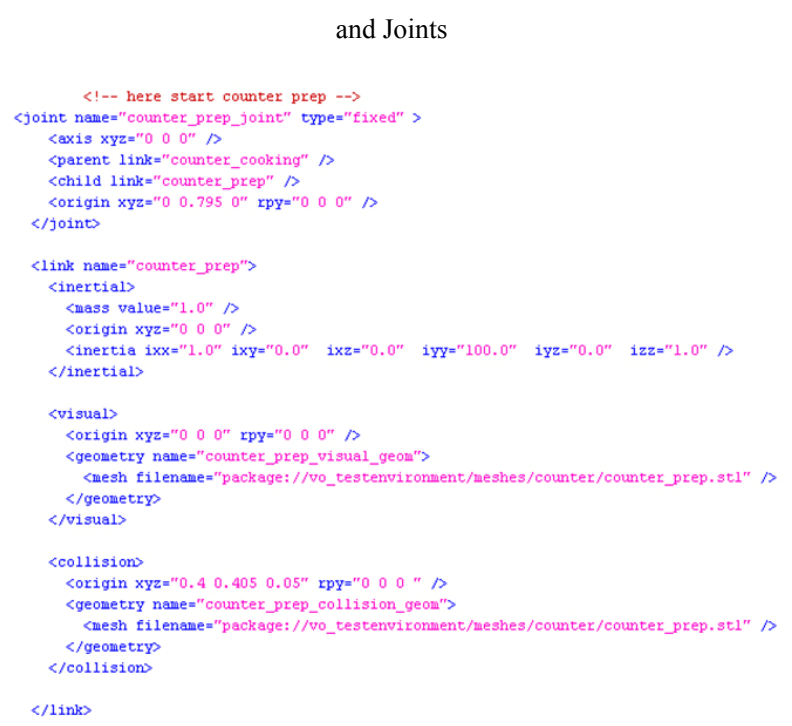

Fig 16 Unified Robot description for Gazebo describing the architectural space

\section{CONCLUSION}

History shows that our environment has always been shaped by the major technological breakthroughs with agriculture leading to first human settlements to the industrial revolution leading to growth of cities. Currently we are on the verge on another major breakthrough in form of ubiquitous technologies. And the urban environment we know of will be restructured as the concepts of ROS/Gazebo and prototypes at building level gets integrated at the urban level. 


\section{REFERENCES}

[1] Joint Programming Initiative Synthesis Paper "More Years, Better Lives- The Potentials and Challenges of Demografic Change", German Federal Ministry of Education and Research, 2010

[2] Want, R., "An Introduction to Ubiquitous Computing", Ubiquitous Computing Fundamentals, pp. 1-36, 2010.

[3]The Day of the Cyborg, Documentary Series, Website: http://www.zdfenterprises.de/de/der tag des_cyborg.40.ht m?template $=d \_z d f e \_p r o g r a m \& s k i p=117 \&$ sort $=$ sheadline en\&order=asc \&from=40\&l=de, last visited: 11.03.2011.

[4] Masamune, S. "The Ghost in the Shell" Kodansha, 1991

[5] V. Callaghan, A. Kameas, A. Reyes, D. Royo, M. Weber "Intelligent Environments 2009: Proceedings of the 5th International Conference on Intelligent Environments, Volume 2 Ambient Intelligence and Smart Environments", Spain, 2009

[6] R. Krawitz, "Media competency as 4th cultural technology", Website: http://www.medienkompetenzrlp.de/Mefo3/neuref.htm, last visited: 11.03.2011.

[7] US Census Bureau, International Data Base for Japan,

Website: http://www.census.gov/ipc/www/idb/country.php, last visited: 12.03 .2011

[8] T. Linner, B. Ellmann, T. Bock, "Ubiquitous Life Support Systems for an Ageing Society in Japan. In: Ambient Assisted Living: Advanced Technologies and Societal Change". Edited by R. Wichert, B. Eberhardt, Springer Science + Business Media, pp. 31- 48, Berlin, 2011

[9] First International Workshop on the Urban Internet of Things, Website:

http://www.theinternetofthings.eu/content/firstinternational-workshop-urban-internet-things-urban-iot2010-call-papers-call-demos, last visited: 11.03.2011.

[10] MIT SensableCityLab, Website: http://senseable.mit.edu/, last visited: 11.03.2011.

[11] Linner, T., Kranz, M., Roalter, L., Bock, T. "Compacted and Industrially Customizable Ambient Intelligent Service Units: Typology, Examples and Performance". The 6th International Conference on
Intelligent Environments - IE'10, Kuala Lumpur, Malaysia, July 2010

[12] Moritz, E. F.; Erdt, S.; Strehler, M., Schulz, T., Struck, M., „Bewegungsmotivation oder Kampf dem inneren Schweinehund“, Ambient Assisted Living Congress, Berlin, 2011

[13] Miwa, Y, Yabuno, K, “The Book of Wabot".

[14] Murakami, K., Hasegawa, T, Kurazume, R, Kimuro,Y "A Structured Environment with Sensor Networks for Intelligent Robots", IEEE SENSORS 2008 Conference

[15] Cyberdyne, Prof. Sankai, 2010

[16] Eastman, C., Teicholz, P., Sacks, R., Liston, L “ BIM Handbook - A guide to building information modeling for owners, managers, designers, engineers and contractors", 2008

[17] Mahdavi, A "The technology of sentient buildings", ITU A|Z, Vol:3, No:172, 25-36, 2006

[18] ROS - Introduction, Website: http://www.ros.org/wiki/ROS/Introduction, last visited 12.03.2011 